\title{
Exposure to extreme heat and precipitation events associated with increased risk of hospitalization for asthma in Maryland, U.S.A.
}

Sutyajeet Soneja ${ }^{1}$, Chengsheng Jiang ${ }^{1}$, Jared Fisher ${ }^{2}$, Crystal Romeo Upperman ${ }^{1}$, Clifford Mitchell ${ }^{3}$ and Amir Sapkota ${ }^{1 *}$

\begin{abstract}
Background: Several studies have investigated the association between asthma exacerbations and exposures to ambient temperature and precipitation. However, limited data exists regarding how extreme events, projected to grow in frequency, intensity, and duration in the future in response to our changing climate, will impact the risk of hospitalization for asthma. The objective of our study was to quantify the association between frequency of extreme heat and precipitation events and increased risk of hospitalization for asthma in Maryland between 2000 and 2012.

Methods: We used a time-stratified case-crossover design to examine the association between exposure to extreme heat and precipitation events and risk of hospitalization for asthma (ICD-9 code 493, $n=115,923$ ).

Results: Occurrence of extreme heat events in Maryland increased the risk of same day hospitalization for asthma (lag 0) by $3 \%$ (Odds Ratio (OR): 1.03, $95 \%$ Confidence Interval (Cl): 1.00, 1.07), with a considerably higher risk observed for extreme heat events that occur during summer months (OR: 1.23, 95 \% Cl: 1.15, 1.33). Likewise, summertime extreme precipitation events increased the risk of hospitalization for asthma by $11 \%$ in Maryland (OR: 1.11, $95 \% \mathrm{Cl}: 1.06,1.17$ ). Across age groups, increase in risk for asthma hospitalization from exposure to extreme heat event during the summer months was most pronounced among youth and adults, while those related to extreme precipitation event was highest among $\leq 4$ year olds.
\end{abstract}

Conclusion: Exposure to extreme heat and extreme precipitation events, particularly during summertime, is associated with increased risk of hospitalization for asthma in Maryland. Our results suggest that projected increases in frequency of extreme heat and precipitation event will have significant impact on public health.

Keywords: Asthma, Climate change, Extreme weather, Heat, Hospitalization, Precipitation, Respiratory illness

\section{Background}

The U.S. Centers for Disease Control and Prevention (CDC) reports that 25.5 million Americans are living with asthma, with approximately 439,000 cases resulting in hospitalization annually [1]. Annual costs to the U.S. economy, including loss of productivity, medical expenses, and premature death, is estimated to be $\$ 56$ billion USD

\footnotetext{
* Correspondence: amirsap@umd.edu

${ }^{1}$ Maryland Institute for Applied Environmental Health, University of Maryland School of Public Health, 2234F SPH Building \#255, College Park 20742, MD, USA

Full list of author information is available at the end of the article
}

[2]. In the state of Maryland, over 430,000 adults were living with asthma (9.4\% prevalence) in 2013 [3], with a total annual hospitalization cost exceeding \$66 million USD [4]. An extensive body of literature has shown that exposures to environmental risk factors such as indoor/outdoor allergens (i.e., mold, dander, dust mites, pollen), tobacco smoke, occupational hazards, and air pollution can exacerbate asthma [5-13].

More recent studies have investigated the association between meteorological parameters (e.g., temperature, precipitation) and risk of hospitalization for respiratory health outcomes, including asthma [14-20]. These studies 
have revealed that particular subpopulations, such as the elderly, are disproportionately impacted [17-19]. Changes in temperature can lead to airway obstruction that are associated with asthma attacks, alter onset and length of pollen season, and increase pollen production [21-25]. In addition to temperature, precipitation may also influence the risk of asthma attacks. In particular, several studies have highlighted elevated risk of asthma attacks following major thunderstorms [26-29]. Thunderstorm events, or periods of heavy rainfall and intense wind, are believed to trigger the release of fungal spores that are carried by wind, thereby resulting in increased exposure to these triggers [26-28].

An increasing body of literature, including the most recent Intergovernmental Panel on Climate Change (IPCC) report, suggest that extreme weather events are projected to increase in frequency, intensity, as well as duration in the coming decades in response to our changing climate [30]. While previous studies have investigated the link between daily weather (temperature, precipitation, and thunderstorm) and asthma morbidity, there is limited data regarding how increased frequency of extreme events may impact people that are living with asthma. In this study, we identified extreme heat and precipitation events using location and calendar day specific climatology data based on a 30-year baseline (1960-1989), and examined the associations between the frequency of such extreme events and risk of hospitalization for asthma in the state of Maryland during the 2000 to 2012 period. We further investigated how this association differs across various demographic subgroups (i.e., age groups, gender, and race/ ethnicity) in Maryland with a particular emphasis on the summertime exposure.

\section{Methods}

\section{Extreme heat and precipitation events}

Extreme heat and precipitation events during the study period (2000-2012) were identified as previously described, with slight modifications [31, 32]. In brief, meteorological data (Additional file 1: Figure SA.1) was obtained from the National Climatic Data Center [33] for the period of 1960-2012. Using daily maximum temperature (TMAX) and total precipitation (PRCP) for the 1960 to 1989 period, county-specific 30-year baselines for TMAX and PRCP for a given calendar day were determined using a 31-day window that centered on the particular calendar day. For example, to compute Garrett County's July $15^{\text {th }}$ baseline TMAX and PRCP, we compiled all daily TMAX and PRCP values for Garrett County from July $1^{\text {st }}$ to July $31^{\text {st }}$ between 1960 and 1989 . We then identified the $95^{\text {th }}$ percentile (TMAX) and $90^{\text {th }}$ percentile (PRCP) value of this distribution and referred to them as Extreme Temperature Threshold $95^{\text {th }}$ percentile (ETT95), and Extreme Precipitation Threshold $90^{\text {th }}$ percentile (EPT95), respectively. Daily TMAX and PRCP values for each counties during the study period (2000-2012) were compared to their respective daily $\mathrm{ETT}_{95}$ and $\mathrm{EPT}_{90}$ and assigned a value of "1" if they exceeded the threshold and identified as an extreme event (of heat or precipitation). This data was linked to the asthma hospitalization data based on the county of residence.

\section{Hospitalization data}

We obtained inpatient hospital admission data for asthma (International Classification of Diseases, Ninth Revision (ICD-9) principal diagnosis code: 493) from the Maryland Department of Health and Mental Hygiene. Hospitalization admissions spanned January 1, 2000 to December 14, 2012 for the entire state of Maryland. For each record, additional information was extracted including county of residence, age, gender, race/ethnicity, and hospital admission date. The institutional review board at the University of Maryland, College Park as well as the Maryland Department of Mental Health and Hygiene approved acquisition and use of all data.

\section{Statistical analysis}

A time-stratified case-crossover analysis [34] was utilized to assess the association between exposure to extreme events and the risk of hospitalization for asthma. For selection of control periods, the study time frame (2000-2012) was divided into consecutive 28-day intervals. For each hospitalization admission date, three control days matched by day of week occurring on 7, 14, or 21 days before, after, or a combination of both around the admission day were assigned within the same interval. Conditional logistic regression models, performed in SAS (Version 9.3, Cary, $\mathrm{NC}$ ), were used to calculate association between exposure to extreme heat and precipitation event and risk of same day (lag 0) hospitalization for asthma. In an overall analysis, we investigated the association between exposure to extreme heat and precipitation events and risk of hospitalization for asthma. We further stratified the analysis to investigate how the risk associated with extreme heat and precipitation events varied across season (spring, summer, autumn, winter), age ( $\leq 4,5$ to 17,18 to $64, \geq 65$ ), race/ethnicity (non-Hispanic white, non-Hispanic black, and Hispanic), and gender groups since prior studies have shown the risk to differ across these factors [13, 14, 17].

Additional sensitivity analyses were conducted examining lag periods ( 1 day, 2 day, and $0-2$ days) and combinations of the thresholds utilized for extreme heat and precipitation $\left(90^{\text {th }}, 95^{\text {th }}\right.$, and $99^{\text {th }}$ percentiles).

\section{Results}

There were a total of 115,923 inpatient cases of hospitalization for asthma in Maryland from 2000 to 
2012 (Table 1). Autumn had the highest percentage of cases $(29 \%)$ and summer the least (18\%). The median age with interquartile range (IQR) for all cases was 44 years of age (12-60) (Table 1). Considerable seasonal variability was observed across all age groups. For example, compared to summer, autumn had 131 and $267 \%$ higher hospital admissions for the $\leq 4$ and 5 to 18 years subgroups. However, increases were considerably lower (32 and $14 \%$ ) for the 18 to 64 and $\geq 65$ years of age groups.

The association between exposure to extreme heat event and increased risk of hospitalization for asthma is shown in Fig. 1 for the 2000 to 2012 period overall, and for summer months during the same period. In the overall analysis, exposure to extreme heat event in Maryland was associated with a $3 \%$ increase in the risk of hospital admission for asthma (Odds Ratio (OR): 1.03, $95 \%$ Confidence Interval (95\% CI): 1.00, 1.07). This risk was considerably higher when the analysis was restricted to the summer season (OR: 1.23, 95 \% CI: 1.15, 1.33), with a noted heterogeneity between seasons (results not shown). This trend of higher risk during summer months was consistent across gender, age groups, and race, with a noted exception observed for Hispanics (Fig. 1). Among race groups, the risk of hospitalization for asthma associated with summertime extreme heat event was highest for non-Hispanic whites $(\mathrm{OR}=1.33,95 \% \mathrm{CI}: 1.19,1.49)$, followed by non-Hispanic blacks (OR: 1.20, 95 \% CI: 1.08, 1.33). Such increases in risk were not observed among Hispanics (OR: 0.67, 95 \% CI: 0.41, 1.09). Likewise, the increase in risk associated with summertime extreme heat event was highest among the 5 to 17 years age group (OR: 1.36, 95 \% CI: 1.05, 1.77).

The corresponding results for exposure to extreme precipitation events, which were included in the same model as extreme heat, and risk of hospitalization for asthma is depicted in Fig. 2. In the overall analysis, extreme precipitation was not associated with an increased risk of hospitalization for asthma (OR: 1.00, $95 \% \mathrm{CI}$ : $0.98,1.02)$. However, during the summer months, exposure to extreme precipitation event was associated with an $11 \%$ increase in risk of hospitalization for asthma (OR: 1.11, 95 \% CI: 1.06, 1.17). The risk associated with the summertime extreme precipitation event was similar for gender (male vs. female) and race/ethnicity (nonHispanic blacks, non-Hispanic whites, and Hispanics), although the increased risk was not statistically significant among Hispanics. Across age groups, we observed slightly higher risk among the youngest age group ( $\leq 4$ years of age OR: $1.20,95 \%$ CI: $1.05,1.37)$ compared to the other 3 subgroups ( 5 to 17 years of age OR: $1.11,95 \%$ CI: $0.94,1.30 ; 18$ to 64 years of age OR: 1.11, $95 \%$ CI: 1.04, 1.18; and $\geq 65$ years of age OR: 1.07 , 95 \% CI: 0.96, 1.19).

Table 1 Demographic Characteristics of Hospitalizations for Asthma in Maryland: 2000 to 2012

\begin{tabular}{|c|c|c|c|c|c|}
\hline \multirow[b]{3}{*}{ Characteristic } & \multicolumn{4}{|c|}{ Hospitalizations-No. (\%) } & \multirow[b]{3}{*}{$\begin{array}{l}\text { Total } \\
(n=115,923)\end{array}$} \\
\hline & \multicolumn{4}{|c|}{ Segmented by Season ${ }^{a}$} & \\
\hline & $\begin{array}{l}\text { Winter } \\
(n=30,436)\end{array}$ & $\begin{array}{l}\text { Spring } \\
(n=31,103)\end{array}$ & $\begin{array}{l}\text { Summer } \\
(n=20,776)\end{array}$ & $\begin{array}{l}\text { Autumn } \\
(n=33,608)\end{array}$ & \\
\hline \multicolumn{6}{|l|}{ Gender $^{\mathrm{b}}$} \\
\hline Female & $19,326(64)$ & $18,954(61)$ & $13,081(63)$ & $19,334(58)$ & $70,695(61)$ \\
\hline Male & $11,110(36)$ & $12,148(39)$ & $7,695(37)$ & $14,273(42)$ & $45,226(39)$ \\
\hline Age at hospitalization, median (IQR), yrs ${ }^{c}$ & $47(20-62)$ & $44(12-60)$ & $47(27-61)$ & $37(7-55)$ & $44(12-60)$ \\
\hline \multicolumn{6}{|l|}{ Age Group ${ }^{d}$} \\
\hline$\leq 4$ & 4,397 (15) & $4,841(16)$ & $2,663(13)$ & $6,142(18)$ & $18,043(16)$ \\
\hline 5 to 17 & $3,350(11)$ & $4,669(15)$ & $1,846(9)$ & $6,784(20)$ & $16,649(14)$ \\
\hline 18 to 64 & $16,256(53)$ & $15,400(50)$ & $11,993(58)$ & $15,813(47)$ & $59,462(51)$ \\
\hline$\geq 65$ & $6,433(21)$ & $6,192(20)$ & $4,274(21)$ & $4,869(15)$ & $21,768(19)$ \\
\hline \multicolumn{6}{|l|}{ Race/Ethnicity } \\
\hline Non-Hispanic White & $13,320(44)$ & $12,930(42)$ & $8,132(39)$ & $12,769(38)$ & $47,151(41)$ \\
\hline Non-Hispanic Black & $14,513(48)$ & $15,296(49)$ & $10,913(53)$ & $17,625(52)$ & $58,347(50)$ \\
\hline Hispanic & $754(3)$ & 879 (3) & $446(2)$ & $968(3)$ & $3,047(3)$ \\
\hline Other & $860(3)$ & 957 (3) & $545(3)$ & 1,117 (3) & $3,479(3)$ \\
\hline Unknown & 989 (3) & $1,041(3)$ & $740(4)$ & $1,129(3)$ & 3,899 (3) \\
\hline
\end{tabular}

Abbreviations: IQR Interquartile Range, yrs years

${ }^{a}$ Seasons are winter (December-February), spring (March-May), summer (June-August), and autumn (September-November)

bunknown $(n=1)$ for spring season; unknown $(n=1)$ for autumn season

${ }^{c} 2,604$ age observations were excluded due to age $<1$ year old, and were thus unknown

dUnknown $(n=1)$ for spring season 


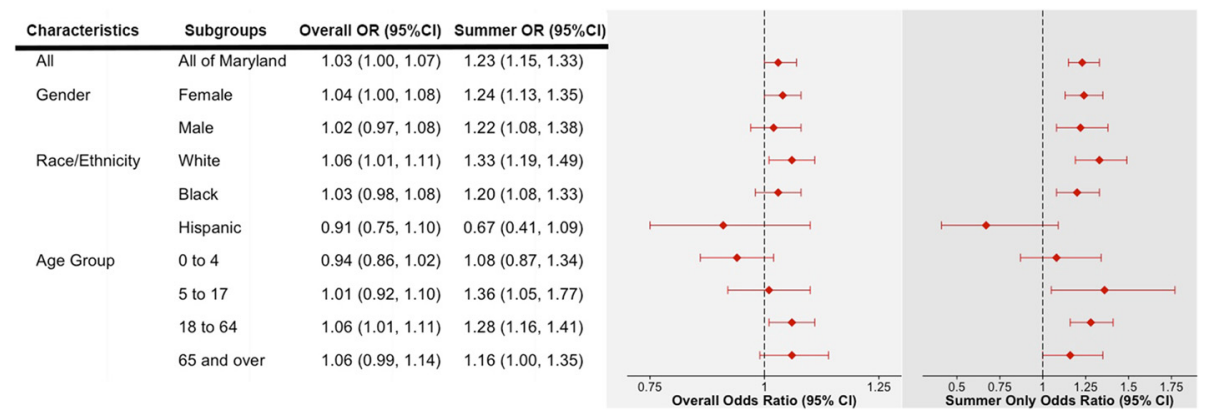

Fig. 1 Odds Ratios (ORs) and $95 \%$ Confidence Interval (95\% Cl) for Exposure to Extreme Heat Events and Risk of Hospitalization for Asthma in Maryland Between 2000 and 2012, adjusted for extreme precipitation event

The results of the sensitivity analyses, presented in the appendix), using different lag structures (Additional file 1: Table SA.1) did not change the results substantially. We have provided results from additional sensitivity analysis (Additional file 1: Table SA.2), where extreme events were identified using different thresholds (eg $90^{\text {th }}$, $95^{\text {th }}$, and $99^{\text {th }}$ percentiles). This did not change our overall conclusions. Also, findings for other seasons are presented within the appendix (Additional file 1: Table SA.3).

\section{Discussion}

Previous studies have shown that the frequency, intensity, as well as the length of extreme events will continue to increase in the foreseeable future in response to a changing climate [30]. In this study, we investigated how increases in frequency of extreme heat and precipitation events are related to the risk of hospitalization for asthma in Maryland. Such information is needed for estimating projected rise in disease burden in the future in response to the increases in frequency of extreme events, as well as to inform local adaptation strategies. Our results show that exposure to extreme heat events is associated with an elevated risk of hospitalization for asthma in Maryland. Increases in risk were considerably higher for summertime extreme heat events. Exposure to extreme precipitation events was not associated with an elevated risk of hospitalization for asthma in our overall analysis with a noted exception for those that were very young ( $\leq 4$ years of age). However, we did observe consistently higher and statistically significant risks of hospitalization for asthma associated with summertime extreme precipitation events in most subgroups.

Summer months are associated with higher concentration of many important pollutants, such as ground level ozone, that are related to airway inflammation, asthma exacerbation [35-37], and other acute respiratory outcomes [38-41]. Previous studies have shown that higher temperature contributes to elevated ozone concentrations [9, 38]. Therefore, the observed increased risk of hospitalization for asthma associated with the exposure to extreme heat events may be explained, in part, by exposure to ground-level ozone. This is supported by the fact that the increases in summertime risk are more pronounced in children 5 to 17 years of age followed by adults 18 to 64 years of age, two groups that we expect would be the most active, but not in the very young of 0 to 4 years of age. The absence of risk observed among Hispanics may be due to very small sample size for this particular subgroup $(n=446)$, so findings for this subgroup should be interpreted cautiously.

In addition to temperature, precipitation events have been shown to influence asthma attacks [26-28, 42].

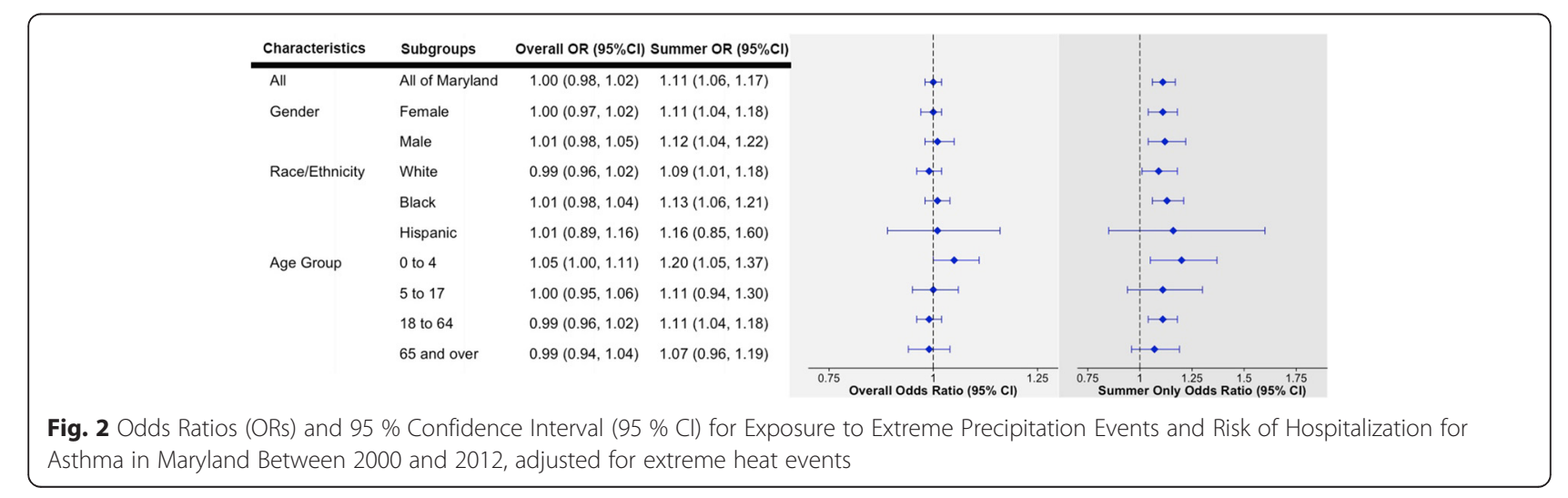


Heavy rainfall may facilitate the release of allergens (e.g., spore plumes and pollen), that contribute to asthma exacerbations [43-47]. Like rainfall, thunderstorms may also contribute to the release of pollen, particularly grass pollen, and thereby contribute to the "thunderstorm asthma" phenomenon [27, 28, 42, 43]. Furthermore, heavy rainfall events could alter the humidity in the environment and contribute to changes in airflow in the respiratory system that could further exacerbate asthma $[23,48,49]$. While our study did not specifically classify extreme precipitation events as a thunderstorm event, it is conceivable that there is significant overlap between the two. The fact that extreme precipitation related risk was evident only during summertime is supported by the previous studies that have tied thunderstorm asthma with grass pollen [27, 28, 42, 43]. Our findings regarding the most consistent increase in risk of hospitalization for asthma related to extreme precipitation events among the youngest age group is in agreement with previous literature that have reported similar findings for thunderstorm-associated asthma [43]. Mounting evidence suggests that this age group may be susceptible to allergen sensitization and allergic disease induction [50].

This study utilized exposure metrics that were derived based on three decades (1960-1989) of baseline data and was specific to each calendar day and county. Furthermore, the hospitalization data encompassed a reasonably long time frame (13 years), which included considerable variability in both the exposures and outcome data. The analysis controlled for confounding at the individual level by utilizing the case-crossover design $[34,51]$. There are some limitations of the study that merit further discussion. The exposure metric used was dichotomous in nature, and did not account for the intensity as well as duration of the event. Also, as the spatial resolution of our exposure metric was county level, there is a potential for exposure misclassification as it does not distinguish heterogeneity in exposure within county, particularly larger counties that have both rural and urban areas. Future research needs to consider finer spatial resolution, such as ZIP code or census track. Our geographic area was relatively small as well (24 counties in Maryland) and the ability to distinguish between recurrent hospitalizations and information on duration of stay were unavailable for this study. Use of the ICD code for asthma diagnosis could be a point of concern for those less than 4 years of age as diagnosing asthma in that age category can be difficult [52], thus future research should seek to conduct further analysis for this age group using different classification methods.

As more and more people are living longer, often with chronic diseases such as asthma, understanding how such vulnerable populations will be differentially impacted by increases in the frequency of extreme events that are projected to rise in response to our changing climate is a public health priority. Building effective adaptation strategies that are based on disease forecast models and early warning systems require an in-depth understanding of the exposure response relationships as well extreme event projections that may not be uniform across geographic regions. Our findings build upon the previous literature related to meteorological parameters (maximum daily temperature, precipitation) and asthma exacerbation by providing exposure response functions for exposure to extreme events and increased risk of hospitalization for asthma. These findings are relevant in the context of our changing climate where such events are expected to rise in frequency, duration, and intensity.

\section{Conclusion}

Our findings suggest that exposures to increased frequency of extreme heat and precipitation events are associated with elevated risk of hospitalization for asthma in Maryland, particularly during summertime. While summertime extreme heat event related risk is most pronounced among youths and adults, extreme precipitation event related risk is most pronounced among the youngest age group $(\leq 4$ years of age). Local adaptation strategies need to account for such differential vulnerability.

\section{Additional file}

Additional file 1: Supplemental Materials. Table A.1. Sensitivity Analysis Showing the Impact of Lag Structures for the Odds Ratios and $95 \%$ Confidence Intervals. Table A.2. Sensitivity analysis across extreme threshold combinations for overall model for the entire state of Maryland. Table A.3. Analysis Showing the Odds Ratios and $95 \%$ Confidence Intervals for Exposure to Extreme Events for the Spring, Winter, and Autumn seasons. Figure A.1. Location of weather stations in Maryland. Figure A.2. Monthly averaged number of extreme heat and extreme precipitation events by county, for overall years and during summer months only (2000-2012). (DOCX 62764 kb)

\section{Abbreviations}

95 \% Cl: 95 \% Confidence Interval; CDC: United States Center for Disease Control and Prevention; EPT 90 : Extreme Precipitation Threshold $90^{\text {th }}$ percentile; ETT 95: Extreme Heat Threshold 95 ${ }^{\text {th }}$ percentile; ICD-9: International Classification of Diseases, Ninth Revision; IPCC: United Nations Intergovernmental Panel on Climate Change; IQR: interquartile range; OR: Odds Ratio; PRCP: daily total precipitation; TMAX: maximum daily temperature (TMAX); USD: United states Dollar; yrs: years.

\section{Competing interests}

The authors declare that they have no competing interests.

\section{Authors' contributions}

The manuscript was written through contributions of all authors. All authors have given approval to the final version of the manuscript. Specific contributions were as follows: SS performed data analysis and drafted the manuscript; CJ and JF assisted with data analysis; CRU assisted with the application of the exposure metric and writing of the paper; CM was responsible for acquisition of the health data, co-designing the study and drafting of manuscript; and AS designed the study, supervised data analysis, and co-wrote the manuscript. 


\section{Acknowledgements}

The contents of this article are solely the responsibility of the authors and do not necessarily represent the official views of the CDC or the Maryland Department of Health and Mental Hygiene.

\section{Funding}

This work was funded by the Centers for Disease Control and Prevention (CDC) 1UE1EH001049-01

\section{Author details}

'Maryland Institute for Applied Environmental Health, University of Maryland School of Public Health, 2234F SPH Building \#255, College Park 20742, MD, USA. ${ }^{2}$ Department of Epidemiology, University of Maryland School of Public Health, College Park 20742, MD, USA. ${ }^{3}$ Maryland Department of Health and Mental Hygiene, Prevention and Health Promotion Administration, Baltimore, MD, USA.

Received: 7 January 2016 Accepted: 22 April 2016 Published online: 27 April 2016

\section{References}

1. U.S. CDC. FastStats Asthma Facts-CDC's National Center for Health Statistics [Internet]. 2015 [accessed 2015 Jul 6]. Available from: http://www. cdc.gov/nchs/fastats/asthma.htm.

2. Barnett SBL, Nurmagambetov TA. Costs of asthma in the united states: 2002-2007. J Allergy Clin Immunol. 2011;127:145-52.

3. U.S. CDC. Most Recent Asthma State Data-CDC's National Center for Environmental Health [Internet]. 2015 [accessed 2015 Jul 29]. Available from: http://www.cdc.gov/asthma/most recent_data_states.htm.

4. Bankoski A, Hess-Mutinda R, McEachern Y, Cheryl De Pinto M. Asthma in Maryland: Maryland Asthma Surveillance Report [Internet]. Baltimore, Maryland: The Maryland Asthma Control Program, Family Health Administration, Maryland Department of Health and Mental Hygiene; 2012 Jun. Available from: http://phpa.dhmh.maryland.gov/mch/Documents/ Asthma_in_Maryland-2011.pdf.

5. Beggs PJ, Bambrick HJ. Is the global rise of asthma an early impact of anthropogenic climate change? Environ Health Perspect. 2005;113:915-9.

6. Breysse PN, Diette GB, Matsui EC, Butz AM, Hansel NN, McCormack MC. Indoor Air pollution and asthma in children. Proc Am Thorac Soc. 2010;7:102-6.

7. Corden JM, Millington WM. The long-term trends and seasonal variation of the aeroallergen alternaria in derby. UK Aerobiologia. 2001;17:127-36.

8. D'Amato $\mathrm{G}$, Cecchi L. Effects of climate change on environmental factors in respiratory allergic diseases. Clin Exp Allergy. 2008;38:1264-74.

9. D'Amato G, Cecchi L, D'Amato M, Liccardi G. Urban air pollution and climate change as environmental risk factors of respiratory allergy: an update. J Investig Allergol Clin Immunol. 2010;20:95-102.

10. Diette GB, McCormack MC, Hansel NN, Breysse PN, Matsui EC. Environmental issues in managing asthma. Respir Care. 2008:53:602-17.

11. Gilmour MI, Jaakkola MS, London SJ, Nel AE, Rogers CA. How exposure to environmental tobacco smoke, outdoor Air pollutants, and increased pollen burdens influences the incidence of asthma. Environ Health Perspect. 2006;114:627-33

12. Rogerieux F, Godfrin D, Senechal H, Motta AC, Marliere M, Peltre G, et al. Modifications of phleum pratense grass pollen allergens following artificial exposure to gaseous Air pollutants (O3, NO2, SO2). Int Arch Allergy Immunol. 2007;143:127-34

13. Yeatts K, Sly P, Shore S, Weiss S, Martinez F, Geller A, et al. A brief targeted review of susceptibility factors, environmental exposures, asthma incidence, and recommendations for future asthma incidence research. Environ Health Perspect. 2006;114:634-40

14. Ye X, Wolff R, Yu W, Vaneckova P, Pan X, Tong S. Ambient temperature and morbidity: a review of epidemiological evidence. Environ Health Perspect. 2011;120:19-28.

15. Michelozzi P, Accetta G, De Sario M, D'Ippoliti D, Marino C, Baccini M, et al. High temperature and hospitalizations for cardiovascular and respiratory causes in 12 European cities. Am J Respir Crit Care Med. 2009:179:383-9.

16. Green RS, Basu R, Malig B, Broadwin R, Kim JJ, Ostro B. The effect of temperature on hospital admissions in nine California counties. Int J Public Health. 2010;55:113-21.
17. Lin S, Luo M, Walker RJ, Liu X, Hwang S-A, Chinery R. Extreme high temperatures and hospital admissions for respiratory and cardiovascular diseases. Epidemiology. 2009;20:738-46.

18. Gronlund CJ, Zanobetti A, Schwartz JD, Wellenius GA, O'Neill MS. Heat, heat waves, and hospital admissions among the elderly in the united states, 1992-2006. Environ Health Perspect. 2014;122:1187-92.

19. Anderson GB, Dominici F, Wang Y, McCormack MC, Bell ML, Peng RD. Heat-related emergency hospitalizations for respiratory diseases in the Medicare population. Am J Respir Crit Care Med. 2013;187:1098-103.

20. Lin S, Hsu W-H, Van Zutphen AR, Saha S, Luber G, Hwang S-A. Excessive heat and respiratory hospitalizations in New York state: estimating current and future public health burden related to climate change. Environ Health Perspect. 2012;120:1571-7.

21. Cecchi L, D'Amato G, Ayres JG, Galan C, Forastiere F, Forsberg B, et al. Projections of the effects of climate change on allergic asthma: the contribution of aerobiology. Allergy. 2010;65(9):1073-81.

22. Reid CE, Gamble JL. Aeroallergens, allergic disease, and climate change: impacts and adaptation. Ecohealth. 2009;6:458-70.

23. Strauss RH, McFadden ER, Ingram RH, Deal EC, Jaeger JJ. Influence of heat and humidity on the airway obstruction induced by exercise in asthma. J Clin Invest. 1978:61:433-40.

24. Wang $Y$-C, Lin Y-K. Temperature effects on outpatient visits of respiratory diseases, asthma, and chronic airway obstruction in Taiwan. Int J Biometeorol. 2014;59:815-25.

25. Ziska L, Knowlton K, Rogers C, Dalan D, Tierney N, Elder MA, et al. Recent warming by latitude associated with increased length of ragweed pollen season in central north America. Proc Natl Acad Sci. 2011;108:4248-51.

26. Anderson W, Prescott GJ, Packham S, Mullins J, Brookes M, Seaton A. Asthma admissions and thunderstorms: a study of pollen, fungal spores, rainfall, and ozone. OJM. 2001:94:429-33.

27. Dabrera G, Murray V, Emberlin J, Ayres JG, Collier C, Clewlow Y, et al. Thunderstorm asthma: an overview of the evidence base and implications for public health advice. QJM. 2013;106:207-17.

28. D’Amato G, Liccardi G, Frenguelli G. Thunderstorm-asthma and pollen allergy. Allergy. 2007;62:11-6.

29. Murray V, Venables K, Laing-Morton T, Partridge $M$, Thurston J, Williams D. Epidemic of asthma possibly related to thunderstorms. Br Med J. 1994;309:131.

30. Field CB, Barros V Stocker TF, Dahe Q, Dokken DJ, Ebi KL, Mastrandrea MD, Mach KJ, Plattner G-K, Allen SK, M. Tignor M, and Midgley PM (eds.). IPCC, 2012: Managing the Risks of Extreme Events and Disasters to Advance Climate Change Adaptation. A Special Report of Working Groups I and II of the Intergovernmental Panel on Climate Change. Cambridge, UK, and New York, NY, USA: Cambridge University Press; p. 582. Available at:https://www. ipcc-wg2.gov/SREX/images/uploads/SREX-All_FINAL.pdf.

31. Jiang C, Shaw KS, Upperman CR, Blythe D, Mitchell C, Murtugudde R, et al. Climate change, extreme events and increased risk of salmonellosis in Maryland, USA: evidence for coastal vulnerability. Environ Int. 2015:83:58-62.

32. Romeo Upperman C, Parker J, Jiang C, He X, Murtugudde R, Sapkota A. Frequency of Extreme Heat Event as a Surrogate Exposure Metric for Examining the Human Health Effects of Climate Change. PLoS One [Internet]. PLoS One. 2015:10(12):e0144202. doi:10.1371/journal.pone. 0144202.PMID: 26641244. [accessed 2015 Dec 13];10. Available from: http:// www.ncbi.nlm.nih.gov/pmc/articles/PMC4671592/.

33. NOAA. National Oceanic and Atmospheric Administration National Climatic Data Center (NCDC) [Internet]. 2015 [accessed 2014 Nov 25]. Available from: http://www.ncdc.noaa.gov/cdo-web/.

34. Maclure M, Mittleman MA. Should we use a case-crossover design? Annu Rev Public Health. 2000;21:193-221.

35. Bartoli ML, Vagaggini B, Malagrinò L, Bacci $E$, Cianchetti $S$, Dente $F L$, et al. Baseline airway inflammation may be a determinant of the response to ozone exposure in asthmatic patients. Inhal Toxicol. 2013;25:127-33.

36. Khatri SB, Holquin FC, Ryan PB, Mannino D, Erzurum SC, Teague WG Association of ambient ozone exposure with airway inflammation and allergy in adults with asthma. J Asthma. 2009:46:777-85.

37. Scannell C, Chen L, Aris RM, Tager I, Christian D, Ferrando R, et al. Greater ozone-induced inflammatory responses in subjects with asthma. Am J Respir Crit Care Med. 1996;154:24-9.

38. Ebi KL, McGregor G. Climate change, tropospheric ozone and particulate matter, and health impacts. Environ Health Perspect. 2008;116:1449-55.

39. Pride KR, Peel JL, Robinson BF, Busacker A, Grandpre J, Bisgard KM, et al. Association of short-term exposure to ground-level ozone and respiratory 
outpatient clinic visits in a rural location — Sublette county, Wyoming, 2008-2011. Environ Res. 2015;137:1-7.

40. Sheffield P, Zhou J, Shmool J, Clougherty J. Ambient ozone exposure and children's acute asthma in New York City: a case-crossover analysis. Environmental Health. 2015;14:25. doi:10.1186/s12940-015-0010-2.

41. Filleul L, Cassadou S, Médina S, Fabres P, Lefranc A, Eilstein D, et al. The relation between temperature, ozone, and mortality in nine French cities during the heat wave of 2003. Environ Health Perspect. 2006;114:1344-7.

42. Celenza A, Fothergill J, Kupek E, Shaw RJ. Thunderstorm associated asthma: a detailed analysis of environmental factors. BMJ. 1996;312:604-7.

43. Al-Rubaish AM. Thunderstorm-associated bronchial asthma: a forgotten but very present epidemic. J Fam Commun Med. 2007;14:47-51.

44. Burch M, Levetin E. Effects of meteorological conditions on spore plumes. Int J Biometeorol. 2002;46:107-17.

45. Packe GE, Ayres JG. Asthma outbreak during a thunderstorm. Lancet. 1985;2:199-204.

46. Pringle A. Asthma and the Diversity of Fungal Spores in Air. PLoS Pathog. 2013;9(6):e1003371. . Available from: http://www.ncbi.nlm.nih.gov/pmc/ articles/PMC3675135/.

47. Tosca M, Ruffoni S, Canonica G, Ciprandi G. Asthma exacerbation in children: relationship among pollens, weather, and air pollution. Allergol Immunopathol. 2014;42:362-8,

48. Aitken ML, Marini JJ, Culver BH. Humid air increases airway resistance in asthmatic subjects. West J Med. 1988;149:289-93.

49. Mireku N, Wang Y, Ager J, Reddy RC, Baptist AP. Changes in weather and the effects on pediatric asthma exacerbations. Ann Allergy Asthma Immunol. 2009;103:220-4.

50. Sheffield P, Weinberger KR, Kinney PL. Climate change, aeroallergens, and pediatric allergic disease. Mt Sinai J Med: J Trans Pers Med. 2011;78:78-84.

51. Auger N, Fraser WD, Smargiassi A, Kosatsky T. Ambient heat and sudden infant death: a case-crossover study spanning 30 years in Montreal. Can Environ Health Perspect. 2015;123:712-6.

52. Juhn Y, Kung A, Voigt R, Johnson S. Characterisation of children's asthma status by ICD-9 code and criteria-based medical record review. Prim Care Respir J. 2010;20:79-83.

\section{Submit your next manuscript to BioMed Central and we will help you at every step:}

- We accept pre-submission inquiries

- Our selector tool helps you to find the most relevant journal

- We provide round the clock customer support

- Convenient online submission

- Thorough peer review

- Inclusion in PubMed and all major indexing services

- Maximum visibility for your research

Submit your manuscript at www.biomedcentral.com/submit

) Biomed Central 